\title{
PERSPECTIVE
}

\section{Crisis Pregnancy Centers: Faith Centers Operating in Bad Faith}

\author{
Sonya Borrero, M.D., M.S. ${ }^{1,2,3}$, Susan Frietsche, J.D. ${ }^{4}$, and Christine Dehlendorf, M.D., M.A.S. ${ }^{5}$ \\ 'Division of General Internal Medicine, University of Pittsburgh School of Medicine, Pittsburgh, PA, USA; ${ }^{2}$ Center for Health Equity, Research, and \\ Promotion, VA Pittsburgh Healthcare System, Pittsburgh, PA, USA; ${ }^{3}$ Center for Research on Health Care, University of Pittsburgh, Pittsburgh, PA, USA; \\ ${ }^{4}$ Women's Law Project, Pittsburgh, PA, USA; 5 Department of Family Community Medicine, University of California San Francisco, San Francisco, CA, \\ USA.
}

$\mathrm{J}$ Gen Intern Med 34(1):144-5

DOI: $10.1007 / \mathrm{s} 11606-018-4703-4$

(c) Society of General Internal Medicine (This is a U.S. government work and not under copyright protection in the U.S.; foreign copyright protection may apply) 2018

$\mathrm{O}$ n June 26, 2018, the Supreme Court of the United States issued its long-awaited ruling on a California law that required licensed crisis pregnancy centers (CPCs) to post information about affordable abortion and contraception services offered by the state. The California law also required unlicensed CPCs to disclose that they were not licensed medical clinics. ${ }^{1}$ In a 5-4 vote, the Supreme Court ruled that both provisions of the law violated the clinics' free speech rights under the First Amendment. ${ }^{2}$ Antiabortion advocates celebrated the decision, as CPCs are designed to intercept women with unintended or "crisis" pregnancies and dissuade them from undergoing abortion, ${ }^{3}$ and California's law interfered with this mission.

The moral and legal aspects of abortion have always been hotly contested, and both sides of the ideological divide are entitled to promote their perspective. Crisis pregnancy centers, also known as "pregnancy resource centers" or "pregnancy support centers," are organizations that provide pregnancyrelated counseling and support from an antiabortion perspective. While CPCs have a right to exist and can provide valued emotional, spiritual, and material (e.g., diapers and formula) support for some women, ${ }^{4}$ they often engage in practices that are dubious at best and unethical at worst. ${ }^{5}$

Most CPCs are affiliated with evangelical Christian networks and national antiabortion organizations. Rather than being transparent about their ideological position, however, they typically advertise their services (most famously on highway billboards) using language and images that present themselves as unbiased, comprehensive health centers. ${ }^{5,}{ }^{6}$ Some have their staff wear white coats, although they typically have no medical training. A growing number of centers have obtained licenses to conduct (medically unnecessary) ultrasounds, presumably for the purpose of using fetal images to dissuade women from abortion. ${ }^{5}$ Further, CPCs often employ

Received August 15, 2018

Revised October 3, 2018

Accepted October 4, 2018

Published online October 18, 2018 sophisticated strategies to draw in women who are seeking abortion services, including locating themselves near abortion clinics and using Internet search optimization techniques to elevate their visibility when people search for abortion services. ${ }^{7}$ Women may present to these centers only to find that they neither provide abortion nor refer to abortion providers.

Once a woman has entered a CPC, rather than using solely moral arguments to dissuade her from abortion, staffers use scientific language to advance their mission. Secret shopper studies of CPCs' practices and reviews of their public-facing websites demonstrate that they commonly draw links between abortion and adverse mental health sequelae, breast cancer, and future infertility, ${ }^{8-11}$ (all of which have been discredited by research), with the goal of diverting women with undesired pregnancies from abortion toward adoption or parenting. In one study evaluating CPC practices in Ohio, staff at some centers greatly overstated the risk of miscarriage, suggesting that abortion may therefore be unnecessary or even explicitly recommending to delay abortion given the high likelihood of spontaneous pregnancy loss. ${ }^{9}$

In clouding transparency about the provision of abortion services at their site, withholding information about abortion referral, and providing inaccurate information about the frequency of miscarriage and the safety of abortion, CPCs can obstruct access to timely abortion. Because abortions are medically safer and more accessible within the first trimester, delays in seeking abortion may have significant consequences. Moreover, as CPCs disproportionately attract low-income women and women of color because they advertise free pregnancy-related services, ${ }^{6}$ they can exacerbate observed socioeconomic and racial/ethnic disparities in the ability to access abortion in a safe and timely manner. ${ }^{12}$

Because most CPCs do not charge for services and are not licensed medical practices, they can slip through the cracks of many states' consumer protection statutes and regulations that govern the practice of medicine. While they may not be operating in violation of the law, numerous lawmakers, women's health advocacy organizations, and scholars have decried them as being unethical given their engagement in deceptive practices targeting women at a vulnerable time to propel a particular ideology. Moreover, given their commonplace practice of disseminating inaccurate medical information to women seeking out reproductive health services, CPCs can inappropriately influence women's reproductive health decisions and impact subsequent health outcomes, leading some to 
argue that they pose a public health hazard, ${ }^{3,13}$ though scholarly research on the public health impact of CPCs is limited.

CPCs have been around since the late 1960s, primarily in states that permitted abortion, but their numbers grew significantly during the 1980s and 1990s after the national legalization of abortion. According to the National Abortion Rights Action League (NARAL), an advocacy organization committed to ensuring abortion access, there are an estimated 2500 CPCs in the US, compared to only 800 abortion clinics. In some states, CPCs outnumber abortion providers by ratios as high as 15:1. ${ }^{14}$ Numerous states fund CPCs either directly or indirectly through the sale of "Choose Life" license plates. ${ }^{15}$ For example, in Pennsylvania, taxpayer money directly funds CPCs via legislation that creates grants for "nonprofit agencies whose primary function is to assist pregnant women seeking alternatives to abortion."16 Through this mechanism, the Pennsylvania Department of Human Services gave over \$30 million in grant money to Real Alternatives, a funding conduit for CPCs, from 2012 to 2017. Pennsylvania was also the first of a handful of states to use federal Temporary Assistance for Needy Families (TANF) dollars, which are intended to provide safety-net monies for low-income families, to fund CPCs. Many CPCs throughout the country also receive state and federal funds to promote and conduct abstinence-only sexual education in public schools.

The rise in number of CPCs has coincided with a decrease in abortion clinic numbers primarily due to targeted laws, informed more by ideology than science, designed to shut down abortion clinics or heavily curb their scope of practice. ${ }^{13}$ Numerous states have also mandated scripted counseling by abortion providers that contains unscientific claims about abortion risks. ${ }^{15}$ Thus, women seeking abortion are at risk of being caught between CPCs that choose to provide misleading information and abortion providers who are mandated to do so, curtailing women's ability to make well-informed decisions about their reproductive health.

In the midst of abortion politics and warring ideologies, our mandate as health care professionals is to ensure that patients' interests are at the center of health service delivery and policy and protect their ability to make informed, autonomous health decisions. For some women, especially those who have chosen to parent and/or who share a similar ideological position, CPCs can provide a meaningful support system. Being transparent about their antiabortion commitment, lack of medically trained staff (if applicable), and the limitations of the services they provide are critical first steps that would allow CPCs to operate more ethically. Until they do that, we as primary care providers must help our patients navigate a fraught abortion service climate. For those of us who are uncomfortable or unable to provide pregnancy options counseling and refer women elsewhere, we need to be aware of the prevalence and practices of these centers and educate our patients about where they can get unbiased comprehensive counseling and services. As physician-advocates, we can pressure our federal officials and state representatives to withhold funding from
CPCs until they can assure transparent advertising and refrain from providing scientifically invalid information. As physician-researchers, we can investigate more rigorously the impact of CPCs on women's reproductive decision-making and outcomes. More broadly, we need to be aware of the intrusion on medical practice that CPCs and the Supreme Court ruling create and fight to ensure that informed medical decision making is protected at every opportunity.

Corresponding Author: Sonya Borrero, M.D., M.S.; Center for Research on Health Care University of Pittsburgh, 230 McKee Place, Suite 600, Pittsburgh, PA 15213, USA (e-mail: borrerosp@upmc.edu).

\section{Compliance with ethical standards:}

Conflict of interest: The authors declare no conflicts of interest.

\section{REFERENCES}

1. Assembly Bill No. 775 Chapter 700. Reproductive Fact Act. Available at https://leginfo.legislature.ca.gov/faces/billNavClient.xhtml?bill_ id=201520160AB775. Accessed August 62018.

2. Supreme Court of the United States. National Institute of Family and Life Advocates, v. Becerra. No. 16-1140. Available at: https://www. supremecourt.gov/opinions/17pdf/16-1140_5368.pdf. Accessed August 82018.

3. Increasing access to abortion. Committee Opinion No. 613. American College of Obstetrics and Gynecologists. Obstet Gynecol. 2014;124:1060-5.

4. Kimport K, Dockray PJ, Dodson S. What women seek from a pregnancy resource center. Contraception. 2016;94:168-72.

5. Bryant AG, Swartz JJ. Why crisis pregnancy centers are legal but unethical. AMA J Ethics. 2018;20:269-77.

6. American Public Health Association. Regulating disclosure of services and sponsorship of crisis pregnancy centers. Available at: https://www. apha.org/policies-and-advocacy/public-health-policy-statements/policy-database/2014/07/22/08/33/regulating-disclosure-of-services-andsponsorship-of-crisis-pregnancy-centers. Accessed August 82018.

7. The New York Times. Pregnancy centers gain influence in anti-abortion arena. Available at: https://www.nytimes.com/2013/01/05/health/ pregnancy-centers-gain-influence-in-anti-abortion-fight.html. Accessed August 82018.

8. Bryant AG, Subasri N, Bryant-Comstock K, Levi EE. Crisis pregnancy center websites: Information, misinformation and disinformation. Contraception. 2014;90:605-5.

9. Tsevat D, Miracle J, Gallo M. Evaluation of services at crisis pregnancy centers in Ohio [abstract]. Contraception. 2016;94:391-2.

10. United States House of Representatives Committee on Government Reform. False and misleading health information provided by federally funded pregnancy resource centers. Available at: https:// fedupburlington.files.wordpress.com/2011/07/congressional-reportcpcs.pdf. Accessed August 82018.

11. Bryant AG, Levi EE. Abortion misinformation from crisis pregnancy centers in North Carolina. Contraception. 2012;86:752-6.

12. Dehlendorf C, Harris L. Disparities in Abortion Rates: A Public Health Approach. Am J Publuc Health. 2013; 103:1772-1779.

13. Rosen JD. The public health risks of crisis pregnancy centers. Perspect Sex Reprod Health. 2012;44:202-5.

14. National Abortion Rights Action League. Crisis Pregnancy Center Lie: The insidious threat to reproductive freedom. Available at: https://www. prochoiceamerica.org/wp-content/uploads/2017/04/cpc-report-2015. pdf. Accessed August 82018.

15. Ahmed A. Informed Decision Making and Abortion: Crisis pregnancy centers, informed consent, and the first amendment. Journal of Law, Medicine \& Ethics. 2015;Spring 2015:51-58.

16. The General Assembly of Pennsylvania. General Appropriation Act of 2004. House Bill No. 2579; Session of 2004. Available at: http://www. budget.pa.gov/PublicationsAndReports/Documents/HB2579P4326.pdf. Accessed August 82018. 